International Journal of Pure and Applied Mathematics

Volume 85 No. 5 2013, 869-877

ISSN: $1311-8080$ (printed version); ISSN: 1314-3395 (on-line version)

url: http://www.ijpam.eu

doi: http://dx.doi.org/10.12732/ijpam.v85i5.5

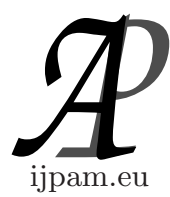

\title{
CULTURES OF CURVES AND STRAIGHT LINES
}

\author{
Yutaka Nishiyama \\ Department of Business Information \\ Faculty of Information Management \\ Osaka University of Economics
}

2, Osumi Higashiyodogawa Osaka, 533-8533, JAPAN

\begin{abstract}
Japanese buildings are constructed with straight lines. European buildings however, tend to have arched rather than straight horizontal lines. Roofs, window frames and the tops of doors are often arched. European buildings are made not from wood but from stone. The reason for these differences is explained by mechanical theory.
\end{abstract}

AMS Subject Classification: 51A02, 00A09, 97A20

Key Words: earthquake, architecture of window frame, curves and straight lines, culture of stone architecture

\section{Cultures Building with Stone and Wood}

It was on my first trip to France in 2000 that I felt that there was something different between European and Japanese buildings. On my short trip of 5 days in Paris and 5 days in Avignon in Southern France, whenever I looked around me, all the doors and windows were arched, which surprised me a little. I have lived in Japan for many years, so I have come to believe that buildings are constructed with straight lines. Pillars stand up vertically from the ground. Beams span the gap between pillars horizontally. Both pillars and beams are straight. Doors and window frames are rectangular, and so are also made up of straight lines. Roofs are sloped but they are roughly straight. The verticals and horizontals used in reinforced concrete buildings are both straight.

Received: January 17, 2013

(c) 2013 Academic Publications, Ltd. url: www.acadpubl.eu 
European buildings, however, are not always horizontally straight. They use arches, that is to say, curved lines. Roofs are round and domed. Window frames and the tops of doors are arched and round, as are bridges. The vertical direction is straight, but horizontally, there are few straight lines to be seen. The arched European buildings that I saw in the paintings at the Louvre were beautiful.

So why are European buildings curved rather than straight? I wondered if perhaps Europeans simply preferred curved lines and other such things, but the question was answered when I went to Avignon in the South of France.

Near Avignon there are small towns such as Arles and Orange, and here there are the remains of buildings constructed during the time of ancient Rome. The outer surfaces of these remains have fallen away, so the architectural structures and construction processes can be easily understood. The reason that the tops of the door and window frames are arched is because these buildings were constructed of stone. This simple fact did not occur to me while I was in Japan. European buildings are made of stone, while Japanese buildings are made of wood or reinforced concrete. When building with stone, the upper parts of door and window frames are rounded, but when using wood, they are straight. The architectural materials therefore determine the form of buildings.

\section{The Climate and Architecture of the United Kingdom}

In 2004 I participated in the International Congress on Mathematical Education (ICME10) in Denmark, and in 2005 I had the opportunity to spend a year performing research in the United Kingdom. At that time, as an amateur, I investigated the forms of European architecture. The characteristics of the windows are as follows. The first thing I noticed was that the proportion of the vertical and horizontal dimensions of windows was larger than in Japan, i.e., they are taller than in Japan. There were even windows twice as tall as they were wide. Also, in Japan, windows may be composed of two panes which can be moved horizontally, but in the UK it is common for windows to have only one pane, which is frequently fixed. Although they sometimes move, it is only by a really small distance. I did wonder whether the ventilation was satisfactory, but it seems that the spaces are well ventilated.

Houses in the UK typically have full central heating systems, and in such cases there is no need for free-standing gas heaters or electric blankets that we generally need to use in Japan. Since there were no small gas heaters, the volume of carbon dioxide produced was also small, and perhaps there wasn't so 
much need for ventilation. Tokyo is at latitude $36^{\circ}$, and London is at $54^{\circ}$. Sapporo is at $43^{\circ}$, so London is situated considerably further north than Hokkaido, but the warm current from the Gulf of Mexico somehow tempers the coldness. As they say, the weather in the UK has "four seasons in a single day"; even if it is warm in the day and the sun is scorching, it can suddenly start raining or become chilly.

The reason the weather changes so drastically is that the landscape is composed of rolling hills without mountains. There are mountains in Scotland to the north, but in England in the south, there are none. In Japan the mountains obstruct the flow of the air, but this doesn't happen in the UK. It is reasonable to regard the UK as being under the influence of a marine climate. According to travel books, the time difference between the UK and Japan is 8 or 9 hours depending on daylight savings. Daylight saving time is not well known in Japan, but it is adopted in the high latitude countries of Northern Europe. Countries with a high latitude have long days in summer and long nights in the winter. In summer, even after $9 \mathrm{pm}$ it may be bright and people continue to enjoy socializing outside. But in the winter, it may be dark by $3 \mathrm{pm}$, and cold. If you visit the UK to study, it's probably a good idea to go for the six months between April and September, and better to move to Italy or similar for the remaining half of the year.

I had a rather interesting experience with the daylight saving time system. I took a short trip from the UK to Belgium for 3 days and 2 nights. After 2 hours and 40 minutes on the European equivalent of the shinkansen (bullet train), I reached the capital of Belgium, Brussels. I left on the 29th of October, and returned on the 31st. The time difference between the UK and Belgium is 1 hour. While away, I set my watch to the local time. I was used to doing this, but October 30 (a Sunday) was the day on which the daylight saving time changeover occurred, and I mixed myself up. Among my mobile phone, wrist watch, the timer on my computer, the wall clock in my lodgings, the clock on the TV, and the clocks in the street, some were changed and others not, and I was confused. When I went for lunch at the college dining hall, there was no one there. I felt bewildered throughout that whole day.

The highest temperature in the summer is around $25^{\circ} \mathrm{C}$, and even considering such days as hot, they never seem to continue for more than 5 days in a row. Since enduring just 5 or so consecutive days of heat is sufficient, they don't have air conditioners in the UK but instead make do with fans. During my stay, I hardly even used my fan. While I was visiting Cambridge, I visited London at the weekends to see galleries and museums.

London is only about 1 hour from Cambridge by train, and during my trips 
it felt like these diesel locomotives were sliding on water. If you're wondering why, it's because, unlike Japan, there's no need to worry about the rails expanding in the heat, so it's not necessary to leave big gaps between the links. The gaps between the rails in the UK are probably small, and I hardly heard the sound of the rails clattering.

The UK only very rarely has noticeable earthquakes, and there is no record in history of an earthquake measuring above 5 on the Richter scale. The surface of the Earth is divided into tens of tectonic plates. Each plate may be $100 \mathrm{~km}$ thick, and they are all moving in their own directions. Minor earthquakes occur at the oceanic ridge where plates are formed, and major ones occur where plates collide, like in the Himalayas, and where plates subduct, or sink down, like in the Japan trench. There are 4 plates in the vicinity of Japan. In Eastern Japan the Pacific plate subducts beneath the North American plate, and in West Japan the Philippine sea plate subducts beneath the Eurasian plate. Also, from the Izu peninsula to the Bonin islands the Pacific plate subducts beneath the Philippine sea plate. When these plates push against each other and exceed the limits of resistance, an earthquake occurs. Since there is a gathering of plates in this way, Japan experiences many earthquakes.

The UK is within the Eurasian plate, and since it is not on a boundary between plates, no large earthquakes occur. King's College in Cambridge was constructed in 1446, so it has over 500 years of history. They say that no earthquake occurred during this long period of time. The buildings don't even have reinforced frames. They are just piles of stone, and they do a good job of standing up, considering that they don't have a reinforced structure. If there were such tall stone buildings in Japan they would be unlikely to survive because of the earthquakes.

\section{The 'This and That' of Window Shapes}

Detached houses and multi-dwelling flats are representative types of residence in the UK. Houses tend to have many rooms and a garden, and one must be of some means to live in one. Flats correspond to Japanese mansions (which are apartments made of brick or stone, and not the huge stately homes known as mansion houses in Europe!) although they are usually bigger than in Japan, and the UK also has what are known as sangaitate (three storey flats) in Japan. The ground floor, first floor, and second floor in the UK correspond to the first, second and third floors in Japan. Houses and flats are mostly constructed by stacking up bricks of a uniform nature. In Cambridge I sometimes saw buildings 
in mid-construction, and while they were attaching bricks with cement they never used any reinforcement. The bricks are just layered up. I wondered whether they were safe, but for a country with no earthquakes, they surely are.

I took some photographs of windows in Cambridge city center. Figure 1 shows a relatively new window frame in a flat. The glass part is rectangular and composed of straight lines, and the bricks are layered in a radial pattern. The bottom part is cut by a straight line. Perhaps stone buildings evolved, and naturally ended up in this current form. The top part of this form of window captured my attention completely. The bricks are arranged prettily and stacked up. Only the top part is layered differently, marring the aesthetic appearance. Figure 2 shows a window frame from a building that I believe is a little older. The glass part is straight and rectangular, but the bricks in the upper part are not straight. Although it is less than $10 \mathrm{~cm}$ tall, there is an arch. I named this the "ultimate window frame".

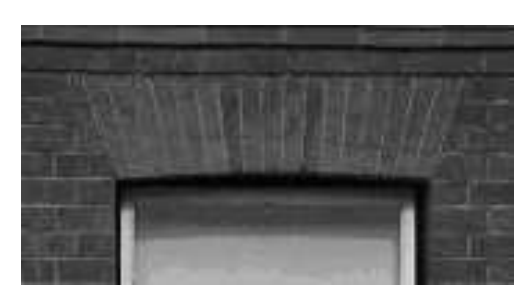

Figure 1: Representative window frame from a private dwelling

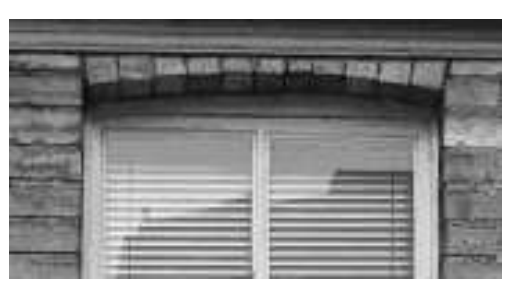

Figure 2: No matter how slight, there is an $\operatorname{arch}($ ultimate window frame)

However, one may also sometimes find window frames like that shown in Figure 3. This incorporates a mechanically impossible method of layering the blocks. In order to hold the blocks horizontally, a force of unlimited strength is required at both ends. If this isn't the case, then the strength of the glass window on the inside must be holding up the blocks and preventing them from falling down.

If you are wondering if all window frames are arched, this is not the case. There were also some constructed with straight lines like that shown in Figure 4. The top part of the opening is horizontal and straight, but the blocks at each end are stacked in slopes. Diagonal arrangements of blocks are dynamically possible, but the blocks along the top are still a concern. Perhaps the glass inside, or a metal frame supports the blocks above so that they don't fall down.

Figure 5 shows an arched gateway. Pay attention to the way it is stacked. 


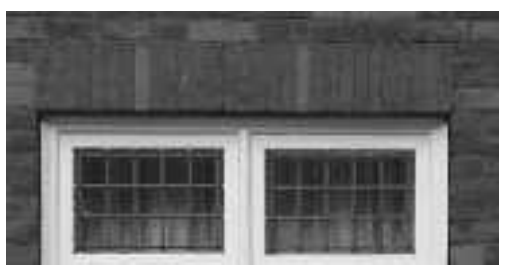

Figure 3: A mechanically impossible window

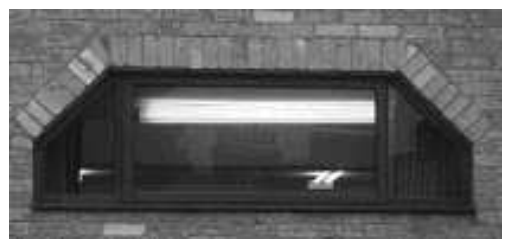

Figure 4: Polygonal window

The stones are stacked in two radial layers. Using an arch rather than a horizontal pattern means that the blocks do not fall down.

Figure 6 shows a window from the Fitzwilliam Museum. Like the gateway shown in Figure 5, the marble blocks are stacked in three radial layers. As a consequence, the window is also arched (in a circle). When stacked in an arch, the top center piece provides great strength, so large pieces of marble were used. The center block is in the exact middle so it is angled vertically at $90^{\circ}$. Blocks cannot be stacked at $90^{\circ}$, so a large piece of marble is probably used in order to give it a slope. The fact that the block in the center is the number one problem when building an arch is considered as the fate of stone architecture.

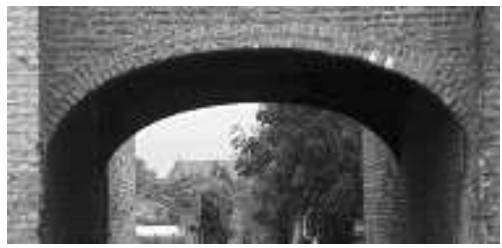

Figure 5: Arched gateway

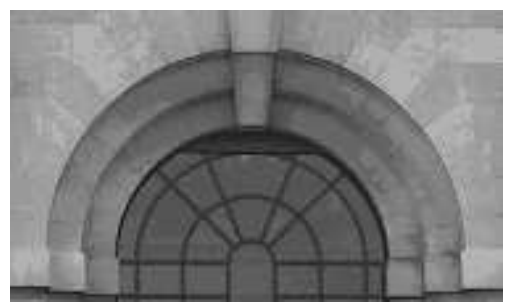

Figure 6: Fitzwilliam Museum (Cambridge)

About 1 hour away from Cambridge by train is the city of Peterborough, which has a Gothic cathedral. Figure 7 shows the window frames from a Gothic church there. Europe has a Christian culture and all the countries have churches and cathedrals. The form of the window frames is not circular like that shown in Figure 6, it is pointed. This is a basic form of Gothic architecture, and allows for the construction of tall buildings. I was interested in this form, and wondered whether it might be a harmonic progression viewed in terms of 
building blocks, i.e. whether it takes the form of a Log function. However, investigating it by tracing over a photograph, I discovered that it is no more than a pair of circular arcs in composition. Instead of using one circular arc with an internal angle of $180^{\circ}$, using two circular arcs with internal angles of $60^{\circ}$ allows the arch to be completed with a reduced burden on the central part. Functionally speaking, a straight horizontal form is known to be the best, but it is impossible to stack stones horizontally, so this dilemma means that they must be stacked in a circles or circular arcs.

Figure 8 shows a theater gateway that I found by chance when visiting Edinburgh in Scotland. Wouldn't the key stone in the centre of the gateway normally spoil the aesthetics? No doubt this is why the architect made the key stone with a lion's tongue design in order to hide it.

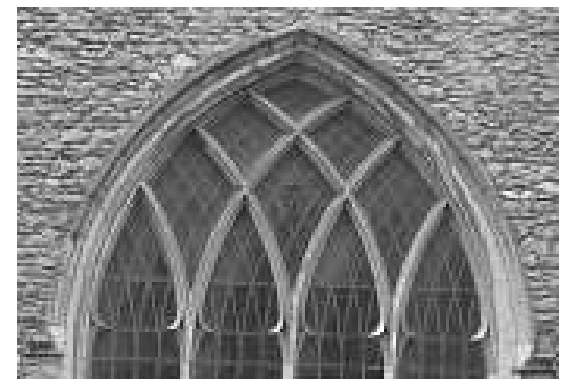

Figure 7: A Gothic window (Peterborough)

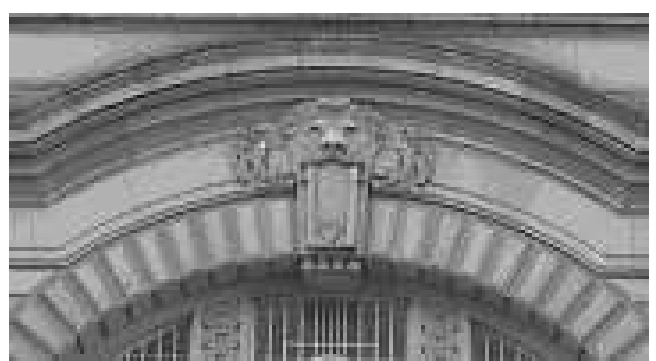

Figure 8: The art of hiding the keystone(Edinburgh)

Figure 9 shows a photograph of the doorway to flat in which I was living. The door is rectangular, with straight vertical and horizontal lines. There is no need to make the glass with a circular arc, but for some reason it is made with an arch. Perhaps this is due to the influence of the culture of stone architecture in Europe.

\section{Stone Buildings as Assets}

All bodies on the surface of the Earth are under the influence of its attractive force. We know just how weak the buildings under the influence of gravity are in a horizontal direction. For example, metal electricity pylons and the wires stretched between them sag under the force of gravity. In order to stretch them out straight, an infinitely large force would be required. This is impossible, so 


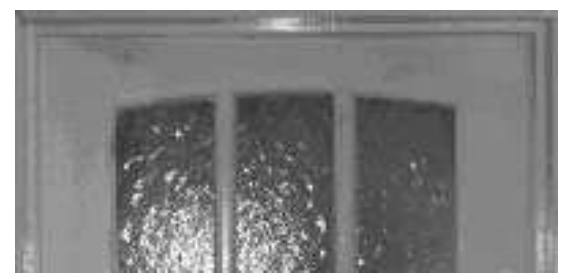

Figure 9: An unnecessary arch in a door(Flat lodgings)

they take the form of catenary curves. Gravity acts in the same way on the beams of buildings, and the deformation due to flexion means that it is difficult for them to be kept horizontal.

For the stones in the top parts of window frames, the weight of the stones themselves and the material above acts to produce a 'bending' force encouraging the central part to droop downwards. The relationship between the stress and distortion when wood or metal is stretched and deformed is expressed as a stress - distortion curve. The initial deformation occurs as an elastic deformation, and the stress - distortion curve has a linear relationship. Increased stress gives rise to plastic deformations and the relationship deviates from a straight line. Further increasing beyond the yielding point causes the material to break.

Wood is pliable and has elasticity. Relatively long pieces are used as material for posts and beams. It is easy to work with, but being easy to burn it has the drawback of being susceptible to fire. Metal is stronger and more elastic than wood, but may be prone to rust. A material combining the properties of metal and stone is reinforced concrete.

Stone is hard, strong, heavy and not an elastic body. It is difficult to work with, and it is hard to obtain long thin pieces of stone like granite, marble and limestone to use as a material horizontally. Granite is used for the outer parts of buildings, while marble and limestone are used for interior decoration. Limestone is a rock composed mostly of calcium carbonate, which is formed from the carbonated lime in the fossils of living creatures with shells and constituents in the sea that fell to the bottom as sediment. The influence of heat on this limestone causes it to transform and re-crystallize as marble. Limestone and marble are both susceptible to acid rain.

I think I understand why European nations strongly desire to enact the Kyoto protocol to prevent global warming which regulates carbon dioxide emissions. They are extremely opposed to reinforced concrete buildings. Metal rusts 
and has a short lifespan, but stone buildings are known to last for 400 to 500 years. While I was studying abroad, the college staff were debating over the construction of a new school building, and hearing that they had no intention of considering using reinforced concrete made a very strong impression on me. 
